\title{
The Effectiveness of Interactive Virtual Reality for Furniture, Fixture, and Equipment Design Communication: An Empirical Study
}

DOI:

10.1108/ECAM-04-2020-0235

\section{Document Version}

Accepted author manuscript

Link to publication record in Manchester Research Explorer

Citation for published version (APA):

Prabhakaran, A., Mahamadu, A. M., Mahdjoubi, L., Manu, P., Che Ibrahim, C. K. I., \& Aigbavboa, C. (2021). The Effectiveness of Interactive Virtual Reality for Furniture, Fixture, and Equipment Design Communication: An Empirical Study. Engineering Construction and Architectural Management. https://doi.org/10.1108/ECAM-04-20200235

\section{Published in:}

Engineering Construction and Architectural Management

\section{Citing this paper}

Please note that where the full-text provided on Manchester Research Explorer is the Author Accepted Manuscript or Proof version this may differ from the final Published version. If citing, it is advised that you check and use the publisher's definitive version.

\section{General rights}

Copyright and moral rights for the publications made accessible in the Research Explorer are retained by the authors and/or other copyright owners and it is a condition of accessing publications that users recognise and abide by the legal requirements associated with these rights.

\section{Takedown policy}

If you believe that this document breaches copyright please refer to the University of Manchester's Takedown Procedures [http://man.ac.uk/04Y6Bo] or contact uml.scholarlycommunications@manchester.ac.uk providing relevant details, so we can investigate your claim.

\section{OPEN ACCESS}




\title{
Engineering Construction and Architectural Management \\ DOI -10.1108/ECAM-04-2020-0235
}

\section{The Effectiveness of Interactive Virtual Reality for Furniture, Fixture, and Equipment Design Communication: An Empirical Study}

\author{
Abhinesh Prabhakaran ${ }^{1^{*}}$, Abdul-Majeed Mahamadu ${ }^{1}$, Lamine Mahdjoubi ${ }^{1}$, Patrick \\ $\mathrm{Manu}^{2}$, Khairil Izam Ibrahim ${ }^{3}$, Clinton Aigbavboa ${ }^{4}$ \\ ${ }^{1}$ Faculty of Environment and Technology, University of the West of England, Bristol, United \\ Kingdom. \\ ${ }^{2}$ School of Mechanical, Aerospace and Civil Engineering, The University of Manchester, \\ Manchester, United Kingdom. \\ ${ }^{3}$ Faculty of Civil Engineering, Universiti Teknologi MARA, Malaysia \\ ${ }^{4}$ Faculty of Engineering and the Built Environment, University of Johannesburg, South Africa
}




\begin{abstract}
Purpose

This study proposes a novel approach to developing an interactive and immersive virtual environment for design communication in the Furniture, Fixture and Equipment (FFE) sector. The study further investigates its effectiveness in enhancing the design communication and coordination between the stakeholder.
\end{abstract}

\title{
Design/methodology/approach
}

Quasi-experimental research was adopted involving 12 FFE professionals, designers and end-users in single-group pre-test-post-test design. The tests were performed primarily to ascertain the impact of the application of interactive Virtual Reality (VR) on delivering furniture design selection and coordination tasks. Further interviews were used to elicit participants' views on the functionality and usefulness of the proposed approach.

\section{Findings}

Findings indicate that an interactive immersive virtual FFE environment: enhances the productivity of the design team through a collaborative virtual workspace offering a synchronised networked design testing and review platform; reduces the time required for the stakeholders to comprehend the design options and test those; enhances the design communication and quality of the design and encourages the collaborative culture in the industry; improves the design satisfaction of the stakeholders, and finally requires significantly less time for design decision making when compared to traditional methods.

\section{Research limitations/Implications}

Future studies should incorporate space planning concepts and explore non-experimental methodologies in a real-life FFE project set-up.

\section{Practical implications}

The proposed approach provides opportunities for enhanced interpretation of design intent in FFE as well as efficiency in design selection and coordination tasks when compared with conventional 2D methods of communication.

\section{Originality/value}

This study proposes a step-change in the way furniture design is communicated and coordinated through an immersive virtual experience. Previous studies have not addressed the issue of impact on design coordination instead focussed on marketing and sales. 


\section{Introduction}

The furniture, fixture and equipment (FFE) sector is a critical segment of the construction industry and remains the single greatest determinant of a building's day-to-day functionality which could conceivably influence the architectural aspects of a facility (Workspace, 2017). The importance of FFE in connecting the built environment, its occupants and the community is increasingly recognised. Studies (e.g. Ergan et al., 2019) have reported that people spend $90 \%$ of their time indoors, which highlights the significance of FFE and their effective arrangements in influencing human experiences in built spaces. Similarly, the contribution of FFE to the economy is also most noteworthy. This sector alone is estimated to contribute about $£ 11$ billion to the UK's GDP (The British Furniture Confederation, 2018). Like all other construction sectors, the FFE supply chain continues to face challenges that impede its competitiveness as well as performance (AMA Research, 2014; Renda et al., 2014). Other reports have reiterated performance decline in the sector, highlighting among other reasons, lack of innovation and reliance on traditional workflows and methods across the delivery cycle (Družić, 2015). Thus, design practice in the FFE sector continues to rely on traditional design tools and resultantly analogue means of design communication, leading to poor stakeholder engagement and satisfaction. According to Barbosa et al. (2017), the lack of innovation and resultant performance declines can be improved through assimilation of digital processes inro the FFE workflow including the adoption of Building Information Modelling (BIM) (NBS, 2016) and Immersive technology (ImT) (Garcia, 2017) in design as well as communication and marketing. Some studies suggest that inefficient communication arises among FFE's stakeholders due to current design practice attributing it to the inability of the stakeholders to interpret $2 \mathrm{D}$ designs leading to reworks, wastage and cost overruns (see Pakhale, 2020). Khanzode, et al., (2012) points out that this mode of design practice will lead to "redundancies, errors and omissions, duplication of information and efforts and difficulties in communicating the designs" with the stakeholders in an effective and timely manner. 
It ought to be noted that the FFE sector's designs are traditionally communicated to the stakeholders using two dimensional (2D) technical drawings, sketches and pictures (Cotey, 2017). Others rely on scaled-down physical prototypes which are costly and cumbersome to develop. Hall and TewdwrJones (2010) report that communication issues that emanate between various stakeholders during the planning phase of a project are mainly due to the poor presentation and visualisation of the information. Studies (Biemans and Brand, 1995; Cotey, 2017) have reported, through the adoption of BIM, the FFE sector is now embracing data-rich digital models to communicate their furniture designs. Similarly, the introduction of BIM into the FFE design workflow has enabled the placing of furniture, documenting and scheduling of the inventory more systematically and easier (Johnston, 2011). However, it could be argued that the sophistication of recent BIM models has reached to an extent were it exceeds critical stakeholders comprehensions, limiting them from being effectively involved in the FFE layout development and reviewing of designs (Walasek and Barszcz, 2017) due to the so-called "black box effect" referring to a system lacking transparency and legibility for the participants (Rahimian et al., 2019). Thus, the previewing of such a data-rich three-dimensional (3D) model on a 2D interface such as paper-based or computer monitors still fails to convey the full depth of an intended design (Laval Virtual, 2017). A typical FFE product selection entails designers using a $2 \mathrm{D}$ or 3D FFE model prevailed on a 2D interface which can either be paper-based or a display followed by stakeholders reviewing those designs on a 2D interface. This process is still inefficient, although it could improve the productivity of this sector by enhancing the stakeholder's understanding of the issues and design intent with a more shared understanding (Prabhakaran et al., 2018).

Rapid developments in ICT, especially immersive technologies i.e. virtual, augmented and mixed-reality (VR/AR/MR applications), has offered new opportunities to address the communication and engagement gap in the FFE sector, which has offered a reliable extension of BIM for more advanced visualisation as well as communication (Rasmussen et al., 2017). Despite the 
potential of BIM-based ImT, there are few examples of their application within the FFE sector. Notwithstanding the well-documented potentials of ImT in the FFE sector, reports have highlighted some limitations with current applications as merely an over-glorified extension of traditional $2 \mathrm{D}$ communications. Thus, the full potential of data-rich BIM models integrated with ImT has not yet been realised to its fullest extent. In bridging this gap, this study explores the effectiveness of an interactive immersive VR environment in enhancing the stakeholder's communication and resulting understanding of an FFE product design choice for a facility. The research thereof proposes a novel methodology for the development and application of a networked interactive virtual environment in FFE design communication.

The remainder of this paper is structured into eleven (11) parts. The first part (1) introduces the study where the motivation is indicated. The second part (2) provides an overview of immersive technology's application in the AEC industry. The third part (3) examines the decision-making behaviour in FFE sector followed by the current state of immersive technology and BIM in FFE sector is discussed in part four (4). In part five (5) we discuss the methodology adopted for this study and the virtual environment architecture. In part six (6) we discuss the details of data collection and analysis methods. In part seven (7) we detail the results of the experiment followed by a detailed discussion in part (8). Further in part nine (9), we provide an insight into the system design, architectural and procurement implication of the study results. In part ten (10) we highlight the limitations of this study followed by conclusion in part eleven (11).

\section{Immersive Technology in the AEC Industry}

Recent improvements and widespread availability of hardware and software technology have contributed to making the use of immersive technologies more viable and worthwhile in the AEC sector (Miltiadis, 2015). Studies by Berg and Vance (2017) suggest that the current state of immersive technology is "mature, stable and importantly usable" in the AEC sector (p.3). Similarly, Gartner's hype cycle refers to the present state of immersive technology as the "plateau of productivity" 
(Panetta, 2017). Various studies have reported that the immersive technologies such as VR and Mixed Reality (MR) can be highly beneficial in AEC activities such as design communication (Wolfartsberger,2019; Kang et al.,2010; de Klerk et al., 2019) and decision making (Hartless et al., 2020), safety assessment and training (Getuli et al., 2020; Hilfert et al.,2016; Azhar, 2017 ), lighting design (Hong and Michalatos, 2016), interior design (Zhang et al 2019), evaluation of construction scenarios (Dawood et al., 2003), facility management (Shi et al., 2020) and so on. As a result of the successful development of applications in these fields, immersive technologies have captured the attention of a growing number of researchers in the AEC domain (Panetta, 2017).

For instances, de Klerk et al., (2019) used VR as a decision-making tool to assist architects during the early stages of ideation and design. In this study, based on the user evaluation among both lay people as well as architects suggests that VR system is a viable tool that can assist the architect in early-stage decisions, which is both easier, satisfying and more effective than CAD-based design tools. However, it ought to be noted that, the learning curve for both VR based and CAD-based systems were identified to be similar. Also, the proposed system can only be used in the concept of ideation and decision making, as the system cannot provide accurate results as that of the CAD-based tools. In another study by Du et al., (2018) assessed the efficiency of VR as a collaborative decisionmaking tool through co-presences in the virtual environment as well as using a live BIM-metadata transfer protocol. This study revealed that co-presence can enhance the communication and decisionmaking process among the stakeholders and improve their level of presence in the virtual environment which reiterates the earlier findings of Saeidi et al., (2019). Furthermore, due to the limitations of the BIM authoring tool used (Revit) for this study, it was impossible to create a visually realistic environment that can deliver a compelling and richer experience for the users. However, it must be noted that earlier studies have pointed out that the visual realism has a profound impact on the user's experience and decision making (Padilla et al., 2018). With the recent development of highly efficient alternative tools (e.g. Enscape VR), it is now possible to have a live link between 
BIM models and the virtual environment without having to compromise the visual realism nor to have multiple iterations to achieve such realism.

In another study Hartless et al., (2020) compared VR and AR technology to assess the behaviour of novice in making building design decisions on supporting wheelchair users. Using a counterbalanced approach with nineteen (19) participants, the authors measured the shift in perceptions of the participants while using two different technologies as well as used video recordings to understand the behavioural patterns of the participants during design modification and decision making in a VR and AR environment. The study revealed that physical exploration using both VR and AR not only delivered a novel design assessment experience but also had an impact on the design decisions made by the participants. Chalhoub and Ayer, (2018) used MR to understand the impact on the productivity and quality of electrical conduit construction as well as to understand the performance of the users in MR when compared to 2D drawings. In a quasi-experiment conducted among eighteen construction personals suggest that MR enabled significantly higher productivity rate, required lesser time to complete the task when compared to $2 \mathrm{D}$ based task and lesser errors during the assembly task when compared to 2D based task.

Further, with the advent of VR, a trend of capitalizing the sophisticated VR application that can deliver a forgiving environment for visualising complex and risky workplace scenarios has also been witnessed. For instance, Getuli et al., (2020) in their study used VR and BIM to enhance the usual manual workspace plaining methodology by simulating the construction activity. A data collection through interviews and by analysing the position tracking, this study revealed the benefits in terms of the sharing of planning and safety-related information between stakeholders and its formal representation in the health and safety plan.VR's potential has also been tested in the context of spatial awareness. Lin et al., (2020) examined the effect of completeness of prior spatial knowledge in people's wayfinding behaviours during an emergency evacuation in an underground metro station 
using virtual reality technology. As evidenced above, several studies have explored the use of immersive technologies in the AEC in general. Despite its usefulness to the FFE sector, there is less research on its applicability and impact, especially as a decision support technology.

\section{Decision-making behaviour in FFE}

FFE plays a significant role in any facility which can constitute approximately $12 \%$ to $16 \%$ construction budget (Fidlschuster, 2007) and sometimes as high as $40 \%$ (i.e. in health care industry which often has the highest budget for FFE products) of the overall construction budget (Fryer, 2012). Thus, FFE is a value driver that must not be underestimated, and attention to the minute design details is critical for successful project delivery (Fryer, 2012). FFE products are often purchased for appeal as well as function. Empirical studies have concluded that the design of an individual piece of FFE as well as how well it blends with a building's design and architecture has a profound influence on a client's decision-making behaviour (Pakarinen and Asikainen, 2001). The decision-making behaviour in FFE is a complex process involving the consideration of restraints such as cost, space availability and matching with the architectural aspects of the facility (Oh et al., 2004). Similarly, various studies have revealed that aesthetics plays a major role in the design choice of furniture (Creusen and Schoormans, 2005). Additionally, due to the significant expense and long product lifecycle of the FFE, clients have to make difficult trade-off decisions with regards to the critical factors such as style and functionality (Oh et al., 2004). Thus, the end product of such a complex decision-making process is the uncertainty arising among the stakeholders over whether they have made the correct design choice. Hall and Tewdwr-Jones (2010) report that one of the greatest reasons for such uncertainties is the beneficiary's inability to comprehend the products in the facility for which those FFE elements are designed.

In this context visual representation using virtual reality plays a critical role in the FFE's design communication as well as design decision process among the stakeholders as opposed by Roy and 
Tai (2003) and Yoon et al., (2010). The role of visualisation in decision making has been emphasized and explored by many researchers. Yoon, (2010) used a web-based VR system to understand the decision-making behaviour in FFE. Despite the system being an exploratory VR, their study revealed that VR based systems can highly assist the decision making while visualising FFE designs. Similarly, a study by Oh et al., (2004) using a web-based VR and conventional formats of twodimensional design reiterates the finding of Yoon (2010). All these studies have undoubtedly concluded that, visualisation using virtual reality technology aid in understanding how well an FFE element blends with the architectural space and how well it serves the function of that space which has a greater impact on the client's decision-making behaviour. Further, Eppler and platts (2009) reported visualisation using virtual reality in design decision can alleviate the three main challenges (cognitive, social and emotional) posed by conventional methods of design visualization. Cumulative evidence reveals that virtual reality has great potential in assisting users during dynamic decision making.

\section{The relevance of immersive technology and BIM in FFE sector}

During the space planning phase of a facility, it is critical that all actors, understand, participate, communicate and collaborate to yield high-quality and optimised outcome (Johansson et al., 2014). Tantawy (2015) points out this process is critical as space is a precious and finite resource, which imposes a huge responsibility on the designers as the facility users will be spending most of their time on these FFE elements, and it should be functional, comfortable and pleasing as well as psychologically and visually pleasant and friendly. Recently, through the adoption of BIM, the FFE sector is now embracing data-rich digital models to communicate their furniture designs (Cotey, 2017). NBS (2016) defines BIM as the "process for creating and managing information on a construction project across the project life cycle where the key output of this process is the digital description of every aspect of the built asset". A vast amount of data is embedded in BIM which 
makes it an excellent source for immersive simulation (Lin et al., 2011). Latest technological advancement has facilitated a BIM-based game engine to stretch its possibilities for immersive environment development, providing opportunities to transform FFE design and communication paradigm. FFE contractors are adopting this digital process as a means to compete in the actual furniture market, which has resulted in a competitive advantage in maximising product reach and client engagement.

The FFE industry is migrating from 2D design to data-rich 3D designs, which have enhanced the collaboration and permitted a better understanding of the design. This collaboration has extended beyond conventional human-human collaboration leading further into human-machine, giving birth to the concept of generative design and its application in space planning. While the concept of generative design is not new in the manufacturing sector, its implication in the FFE design planning is gradually acquiring momentum in recent years. The integration and application of computational intelligence (CI) and artificial intelligence (AI) approaches with BIM for space planning has facilitated automation of human tasks in the design and planning process, thus transforming BIM authoring tools more intelligent and flexible than ever before (Racec et al, 2016). This intelligence and flexibility offered by metaheuristic search algorithms when integrated to BIM tools in FFE design process are offering a new opportunity to FFE designers for testing a plethora of alternative designs which is impossible when done by human designers alone due to time and cost constraints (Racec et al., 2016). Many studies (e.g. Sydora, 2019) in the recent years have focused in the integration of these metaheuristic search algorithms in capturing the interoperable relationship between an FFE design and its virtual spatial object representations in BIM, leveraging opportunities to create programming diagrams and adjacency studies on 3D FFE representations leading to the discovery of novel and high performing design results within a given design system. 
Even though the well-recognised benefits of BIM and algorithm assisted design communication and coordination cannot be ignored, efforts are still imperative to visualise the FFE design more interactively and intuitively (Yan et al., 2011; Du et al., 2018). The lack of three main advancements such as BIM data interaction, human-FFE interaction and human-human interaction in BIM-enabled visualisation methods underlines the need for the aforementioned interactive and intuitive system (Du et al., 2018). Tantawy (2015) claims that the first and foremost requirement for space planning is the ability to visualise space in three dimensions and a keen sense of composition, scale and proportion. Studies such as that by Rasmussen et al., (2017) highlighted the importance of experiencing the architecture space including FFE. Rasmussen et al., (2017) have pointed out that it is not enough to see an architectural space, rather it must be experienced. Some studies (e.g. Li et al., 2017) have pointed out the shortcomings of BIM when used as a technology alone. Li et al. (2017) suggest that poor spatial cognition is a critical shortcoming posed by existing BIM tools. The cognitive latency posed by these BIM tools has a greater role and adverse impact on FFE design decision. In the context of this study, cognitive latency includes cognitive processes such as perception, evaluating design and judgement of the design choice (Chakraborty et al., 2013; Fazio, 1990).

Additive technologies such as VR are capable of bridging this gap by sealing the potential data loss within BIM and improving the stakeholder's comprehensions. Furthermore, integration of this technology is aimed at boosting the dragging productivity of the FFE sector and efficient use of the information (Li et al., 2017). Virtual reality is the utilisation of computer technology to create a simulated environment where the user is completely immersed in the virtual world by simulating as many senses as possible (Jackson, 2015). Thus, the user becomes a part of the virtual or immersed world within its environment whilst they can manipulate or interact with the object. VR technology is capable of providing better communication for the key players involved in the FFE planning of the facility based on the greater design visualisation, contributing to a better understanding of the project 
(Jiao et al., 2013). Cumulative evidence has proved that VR is capable of providing a stronger sense of presence (Hoffman et al., 2003) and can replicate similar user behaviour as in the real-world (Heydarian et al., 2015). Through BIM, data visualisation can be supported by VR for the virtual representation of the FFE products within virtual or real spaces beyond 3D (Greenwood et al., 2008) that can address retrieving and presenting information and can increase efficiency on communication and problem-solving in an interactive and collaborative platform. This could aid the development of digital and virtual prototypes of FFE products that could be used to visualise and appraise designs by stakeholders as well as allow them the opportunity to evaluate alternatives before they are produced, built or incorporated into buildings (Cotey, 2017). ImT can potentially support the evaluation of the aesthetics of FFE products as well as other functional features that may be relevant to various stakeholders including users, clients and contractors when making decisions (Johnson et al., 2010;).

\section{Methodology}

A novel methodology for the development and application of an interactive virtual environment in FFE design communication using BIM and game engine is proposed. Further, this work utilises a quasiexperimental research approach with a one-group pre-test-post-test design to (Fig-1) understand the effectiveness of VR in enhancing the communication and coordination of critical stakeholders and the resulting understanding of the stakeholder's FFE product design choice for a facility when compared with conformist methods like catalogue based (2D based) methods. This research design is widely used in STEM (Allen,2017) and behavioural research aimed to measure changes resulting from experimental treatments or intervention on a given sample (Dimitrov,2003). However, in the context of the FFE domain, there remains a dearth of studies that rely on similar methodologies to explore the use of immersive technologies. In this approach the subject act as their own control where the comparisons are made before the intervention and after the intervention assuming the fact that the difference between pretest and posttest treatment is the due effect of the intervention occurred in the middle (Dimitrov,2003). However, as the participants were not assigned randomly, this design does not 
eliminate the problems of confounding variables (Allen, 2017). Thus, this research design straddles correctional studies and a true experiment in terms of internal validity (Blalock,2018). Studies such as Allen, (2017) have pointed out potential internal validity issues such as regression to the mean. However, the design and context of this study primarily eliminate such threats. For instance, to mitigate the issue of regression to mean, multiple tests (office scenario and meeting room scenario) were adopted for pre-test, post-test measurements (see Ambroggio et al., 2012). Various studies have used this research design to assess the impact of the intervention in the field of engineering (Chalhoub and Ayer,2018 ). Furthermore, these studies have demonstrated the robustness of one group pre-test post-test where multiple experiments scenarios are explored (Chalhoub and Ayer, 2018; Krass, 2016).

\section{Figure 1}

\subsection{Experiment Participants}

Twelve participants $(n=12)$ consisting of specialist FFE designers, architects and end-users participated in this study. The samples consisted of a diverse range of participants with ages ranging from 24 to 60 . In addition to the quantitative measurements, this study provided a qualitative understanding of the proposed VR approach and user reactions which will help in future refinement of the VR simulation developed. The sample size was deemed adequate on the basis of the sample size of similar experiments were the quality of experiment process is the focus rather than quantity and generalisability which is the case of alternative methods such as surveys (Chalhoub and Ayer, 2018). Five (5) of the participants were FFE specialists (manufacturer, designer \& supplier) who had more than twenty-five years of industry experience in designing and delivering efficient spaces for various facilities. Three (3) participants were architects who had more than four years of experience in designing commercial spaces. Four (4) participants were facility end-users who use similar space in their day-to-day activities. All the participants had little or no experience in using VR or any related immersive environment enablers. The participants for this study were recruited by emails and 
personal solicitation. A convenience sampling technique was used to recruit participants due to the peculiarity of the study and the need for participants with specialist or domain understanding of FFE design related tasks. Thus convenience sampling was used to allow researchers to solicit participation from the few but most relevant subjects given this is not guaranteed in randomised sampling (Gogtay and Thatte, 2016) as well as there is a need to purposively choose participants who have requisite knowledge relevant to the study. Below table-1 details the background and attributes of the samples who took part in this study

\section{Table-1}

\subsection{Task}

To achieve a collaborative FFE design proposal environment, participants were grouped into a minimum of two $(n=2)$ in each group based on their availability (table-1). In the pretest stage, each group was presented with two paper-based methods of furniture selection scenario; a) each group were asked to propose furniture for their future office space based on a paper-based 2D office space plan and an FFE catalogue (Fig. 8) consisting of office furniture; b) the same group was asked to propose furniture for a meeting room using paper-based 2D meeting room plan and an FFE catalogue (Fig.8). Further, in the posttest phase, these groups were provided with the same office and meeting rooms from the pre-test, but at this stage instead of paper-based plan and catalogue, they were immersed in the virtual office and meeting room with the aid of the interactive immersive virtual environment using a VR head-mounted display. As the entire VR system for this study was built over a distributed networked system, each participant in that group was able to see each other as avatars and was able to communicate with each other. The samples were asked to select furniture for the space provided using an interactive virtual catalogue (Fig-3). Please refer to section (4.6) for the details of the interactive virtual catalogue. The interactivity offered the participants to fine-tune the geometric parameters such as colour, texture, size etc. as well as BIM meta-properties such as 
manufacturer, cost and product description etc. of the product that they selected. Furthermore, it allowed the users to interact with the transforms to re-position the furniture while in the VR environment. Each group member was able to interact simultaneously allowing the participants to test their design choice. A pre-test questionnaire, post-test questionnaire and open-ended interviews were employed to understand the impact. Before introducing the users to the tasks at both stages, all participants consents were taken, and the details of the test were explained. This enabled the researcher to use the data collected such as time taken to complete each task at each stage, pre-post task questionnaire and open interviews. Further, this study did not consider any counterbalancing measures due to the nature of the task presented. The tasks in this study were not specifically focusing on any specific order of the furniture arrangements rather it was focusing on participants FFE design

choices, their resulting satisfaction and the time taken to propose those design while in a virtual environment when compared to traditional 2D methods.

\subsection{Pretest and Posttest questionnaire}

A pre-test questionnaire was employed to capture; a) previous experience of the participants in using VR or any related immersive technology; b) users' anticipation about the experience of using VR compared to the 2D method in making FFE design choice; c) perception on the shift to paperless design decision process were elicited. The post-test questionnaire focused on eliciting: a) the user experience in the virtual environment; b) perception on shifting to the paperless design decision process. These questionnaires were adopted from similar studies (e.g. Chalhoub and Ayer, 2018) which use mixed reality technology to assess its efficiency over paper-based methods in assembling electrical conduit. Furthermore, a single easy question (SEQ) method was used to elicit the participant's satisfaction level for the design choice they proposed in both pre-test and post-test, which was indicated on a Likert scale and plotted (Fig-10). An SEQ is the most recommended method to capture task satisfaction due to its ease and correlation to other usability metrics (Birkett, 2019). 
Different studies such as that by Sauro (2012) have reported that, despite SEQ's simplicity, it performs more effectively than other complicated measuring tools.

\subsection{Proposed Framework and System Architecture}

To understand the effectiveness of immersive VR in enhancing stakeholder's communication and the resulting understanding of the FFE product design choice for a facility, a prototypical office space, meeting space and related FFE elements were modelled using the most popular and commonly used BIM authoring tool, Autodesk Revit (Autodesk, 2019) (Fig-2). The notion behind using Autodesk Revit

\section{Figure 2}

as the primary modelling tool was to create parametric components that will enable the exchange of meta-data consisting of information such as manufacturer details, cost, product description, warranty, fire rating etc. This data is the information part of BIM and plays a critical role in the BIM ecosystem in analysing the FFE model. Thus, for the true functionality of the BIM as a digital workflow of information from space planning to operation of the space, it is imperative to have all the information relating to the FFE inventories that must be represented in the model and be readily available for the users in the virtual environment to interact and select FFE matching their budget and properties. Unity3D, one of the most popular cross-platform game development engine (Unity3D, 2019) was used as the platform to develop a virtual environment and related human-FFE and human-human interaction. Unity 3D facilitated the use of a primary scripting application programming interface (API) in object-oriented programming (OOP) language, C-sharp (C\#) for the development of the aforementioned interaction. In this study, human-FFE interaction refers to the added function pertaining to human-computer interaction (HCI) that allows the user to interact and manipulate the FFE in a VR environment. Similarly, human-human interaction refers to the interaction of the multiusers or virtual team in the virtual environment between each other as well as with FFE inventories. 
A virtual team can be defined as "a group of people with complementary competencies executing simultaneous, collaborative work process through electronic media without regards to geographical location" (Chinowsky and Rojas, 2003).

A clear and modular structure for the program was achieved due to the OOP nature of the language used (Puri, 2017) that enabled reusability and faster development of the VR application for this study. Some studies (e.g. Prabhakaran et al., 2018) which focused on developing building mechanical services design for facilities utilised similar methodologies in developing the HCI in mixed-reality applications. As the efficacy of the VR environment critically depends on the validity and fidelity of the virtual environment (Virzi et al., 1996), middleware applications must be used as a tool to enhance the texture and other meta elements of the virtual environment, which will offer photorealistic computer graphics ubiquitous for both visual realism and predictability. To this end, texture-enhancing middleware was used to create diffuse, height and normal maps for all the game objects. Using such middleware applications, photorealistic computer graphics ubiquitous for both visual realism and predictability were achieved which enhances the user's "sense of presence".

Wallach et al. (2012) report that this sense of presence assists users in discarding disbelief and forces them to believe in the virtual world. It ought to be noted that "sense of presence" is one of the critical parameters which can increase VR efficacy ( Wallach et al., 2012). Thus, for this study, it is inevitable to use external tools to enhance the "sense of presence". Furthermore, a low-latency multi-user platform called "Photon cloud" (PUN), which is based on a client to server architecture was used to facilitate the development of a scalable real-time networked VR system as well as to enable remote communication using Opus Code (Photon, 2019), facilitating a best possible audio quality. Photon cloud is also a room-based system allowing multiple users (Figs.3 \& 5) to join the same room remotely from any part of the world. The rationale in exclusively implementing a lowlatency system was to improve the sense of presence for the users in the virtual environment, which has a direct impact on the performance of the task presented. The utilisation of photon networking 
engine enables scaling of the virtual environment seamlessly and automatically regardless of the number of the users present in the network.

For testing purpose, HTC Vive (HTC, 2019) was used as the end-user head-mounted display (HMD) device for this study. The inherent six degrees of freedom of the devices allowed the users to walk around in the virtual space and interact with the FFE inventories and their meta-data. However, a teleporting functionality was also provided that will allow users to teleport with the aid of the handheld controller. This feature was incorporated to assist the user group who were not comfortable walking physically in the virtual world. The notion behind using a tethered HMD such as HTC Vive rather than a standalone HMD was not to compromise the realism that jeopardises the sense of presence that has a direct impact on the task. Thus, using HTC Vive as the HMD, the highly realistic graphics rendering was performed by a high-end central processing unit, which is a Windows 10 workstation with an NVIDIA GTX 1070 graphics card, which was not possible when used with a standalone HMD. Thus, a frame rate of $100 \mathrm{fps}$ for all conditions was achieved in the virtual environment, which gave a high-fidelity to the environment as well as eliminating the mentalphysical disorientation of the users.

\subsection{Movement in Virtual Environment}

The users in the virtual world were presented with two modes of movement: a) movement in a virtual world driven by real-world movement; b) teleportation allowing the user to transverse inside the virtual environment without moving physically in the real-world. The users were given the opportunity to choose the mode of movement in the virtual space. It is worth noting that the movement in virtual space driven by real-world movement had the restriction of the user being tethered to a computer through the HMD and cables. However, teleportation could result in VR sickness in some users, as in some cases the human brain is incapable of comprehending the movement in virtual space without being moved in the physical world. However, movement in the 
virtual environment driven by real-world movement is more capable of presenting a higher realism and a resulting sense of presence. Virtual mesh boundaries were drawn to notify users about any approaching static obstacles such as walls. Participants tried both methods before the test and opted for the one most comfortable and suited to them.

\subsection{The interactive user interface in the virtual environment}

Creating a suitable interface that completely immerses the user in the virtual world is a bigger challenge that developers are facing (Winestock, 2018). Diegetic interfaces in VR applications are sometimes hard to achieve and can often result in many issues, such as the user losing track of the interface transform. A diegetic interface is one that exists in the virtual world but is not obviously in the direct view of the user. On the other hand, non -diegetic interfaces are those that cover the entire view angle and are easy to achieve. However, those interfaces could block the view of the user and destroy the immersion experience easily. Thus, for this study, an innovative method was adopted through replicating a digital display with an interactive interface, a.k.a. a handheld tablet displays which is novel in the FFE literature. This enabled the implementation of a diegetic type of interface without compromising the user experience (Fig. 3). The tablet model was anchored to the left-hand controller replicating the real-life usage and the right controller with ray cast aided functionalities such as scrolling, selecting options, drag and dropping of FFE inventories etc. Furthermore, participants reported that using such kind of interface had a huge positive impact on the realism and the sense of presence.

\section{Analysis}

Two types of data were collected from this study; a) perception; b) performance. Perception of the user was collected from the pre-post activity questionnaire, and performance was recorded using time duration taken to complete each task. Details of perception and performance eliciting are reported in 
the next section. Data from these were further subjected to statistical analysis to understand their significant difference from pre-post treatments. In addition, open-ended questionnaires were used to understand full and meaningful answers with respect to participants' knowledge as well as feelings after the VR treatment. These findings are presented in the next section.

\section{Result}

\subsection{Performance}

All the participants were able to perform the task successfully using the 2D plan and FFE catalogue as well as in the virtual environment presented to them. Time taken (Fig.7) by each group during pretest and post-test were recorded to understand the perception of the user when introduced to an immersive digital environment. In the pre-test, time was recorded from the moment the participants were given the 2D plan and FFE catalogue (Fig.8), whereas in the post-test the time was recorded from the moment that the participants joined the distributed room and users were able to see and communicate to each other's avatar. In both stages, the time recording ended when the users declared that they are satisfied with the design choice they proposed. In the VR environment option was provided to save each groups choice, which was later converted into 2D plans (Fig. 9). On an average, each group spent 9 minutes and 8 minutes respectively to complete the paper-based office and meeting room task and 6.3 minutes and 5 minutes, respectively, to complete the office and meeting room tasks in a virtual environment. An independent sample t-test (Table 2) was performed to identify the statistical significance in the duration taken by both control and experiment group to perform each scenario presented to them.

Figure 3, 4, 5, 6 
There was a significant difference in the score for pretest (office space task$\mathrm{M}=542.5, \mathrm{SD}=90.13$ ) and posttest (office space task- $\mathrm{M}=390.5, \mathrm{SD}=47.12$ ) conditions; $\mathrm{t}(10)=3.66, p$ $=0.004$ and pretest (meeting space task- $\mathrm{M}=480, \mathrm{SD}=73.61$ ) and posttest ( meeting space task $\mathrm{M}=303, \mathrm{SD}=26)$ conditions; $\mathrm{t}(10)=5.526, p=0.001$. The design choice of both pretest and posttest were recorded (Fig. 9) to examine any difference in design decision after the treatment.

\section{Table 2}

It ought to be noted that this study did not focus on the principles of space planning, design standards or design rationale such as work triangle followed by designers (Jones and Kapple, 1975) to assess the quality of design choice made by the participants. Rather, this study tries to understand the effectiveness in design decision whilst using VR compared to traditional FFE design selection methods and the resulting satisfaction level of the participants with respect to the design that they proposed.

\section{Figure 7}

\subsection{Perception}

An in-depth literature review revealed that VR technologies are disrupting the construction industry, creating a major shift in design communication. Therefore, it is inevitable to explore the perceptions of the participants. Thus, a pre-post-sessional questionnaire and open-ended questionnaire were employed to understand this perception.

\section{Figure 8}

The pre-session questionnaire revealed that none of the users $(n=12)$ had any experience in using similar technology enablers. Furthermore, all the participants $(n=12)$ felt that VR would be easy to use. Two of the participants reported concerns about the quality and degree of realism that can be achieved compared to real-life settings. More than half $(n=7)$ of the users stated that they would want to use a paper-based selection process for information delivery. Five participants believed that VR 
technology could potentially change the way information is delivered, even though they did not have any previous hands-on experience in using such technologies. Further, pre-treatment design proposal satisfaction for the paper-based design was recorded (Fig. 10). Then, participants were exposed to VR treatment. After completing the design proposing task in the virtual environment, participants completed the post-sessional questionnaire. All the participants $(n=12)$ indicated that they consider VR to be a highly effective medium for design information delivery. Also, it ought to be noted that all of the group proposed a different layout or tested a different design in a VR environment (Fig.9) compared to their paper-based proposal. Most of the participants indicated that design selection using VR encouraged them to test various layouts and a different combination of FFE. Most of the participants preferred a lighter FFE colour when compared to the paper-based method.

One of the users indicated that "I would definitely like to have a brighter room and this virtual experience made me change the colour choice I made in the earlier selection (paper-based). With VR I can visualise the furniture colour with respect to the room colour. This itself is enough to advocate the shift from paper-based to a virtual environment". Another user indicated that "while trying the paper-based I was not sure if the office and meeting area will be spacious enough for user movement, even though all the dimension were marked on the drawings as well as on the FFE catalogue provided. However, while in the second try (VR based) I was able to confidently populate the room with different FFE layouts and with greater satisfaction that space is used in its most efficient way". An FFE supplier commented, "we are very satisfied with the output VR could bring into our business and we will take all necessary steps to set up a virtual space at our facility. Also, we will train our

\section{Figure 9}

staff to develop such contents for our client". Another user reported, "the visual stimuli provided by the digital projection facilitated the process to select the suitable furniture for space. The drawing given did not provide enough input to imagine the space or the furniture fittings which suits the space. 
Based on this demonstration, I would prefer to have VR as a mode of presentation by the FFE contractors for our future projects."

Most of the users indicated that VR enabled them to look into the minute details of the FFE such as edge, colour etc. which were impossible in the paper-based task. Some users $(n=2)$ reported virtual reality sickness. It must be noted that care was taken to maintain a frame rate level of 100 frames per second to eliminate any VR sickness and improve the quality and degree of realism to enhance the resulting sense of presence. Further interviews with the users $(n=2)$ who reported VR sickness revealed that a certain physical condition is responsible for the effect and it is not the virtual environment which has any direct relationship with the experience. A majority of the users identified that the virtual environment provided extreme flexibility in choosing furniture based on their texture, colour and aesthetics as well as based on the interior space and colour of the rooms which was impossible when done through conformist methods. All the users unanimously agreed that they would prefer to shift to a VR based decision process for future engagements.

\section{Figure 10}

Furthermore, users reported that the virtual presence of the other participants in the group encouraged the effective testing of different choices, the sharing of their design choice and the visualisation of each design choice simultaneously. One of the FFE contractors reported that "the possibilities of remote communication and visualisation opens up the window for us to collaborate with our FFE designer/manufacturer who is located hundreds of miles away from us. Usually, we have to send one of our team members to their facility to discuss the design which is financially as well as environmentally unfriendly. We wish to develop this tool further and include it in our supply chain workflow”. The post-session questionnaire also revealed that all the participants had a higher level of satisfaction (Fig. 10) with the design that they proposed compared to the paper-based proposal. However, few participants $(n=2$, user $6 \& 7)$ reported the same level of satisfaction 
compared to the pre-test. It worth noting that these participants earlier reported the VR sickness whilst performing the task. This could have potentially influenced their user experience, which made them report the same level of satisfaction compared to the pre-test. Some of the users also $(n=3)$ reported that the chosen HMD felt bulky for long-term usage. An independent sample t-test (Table 3) was performed to identify the statistical significance in the difference in pre-post-treatment satisfaction levels. There was a significant difference in the score for pre-treatment $\mathrm{M}=2.833, \mathrm{SD}=0.577$ and posttreatment $\mathrm{M}=4, \mathrm{SD}=0.603$ conditions; $\mathrm{t}(22)=-4.841, \mathrm{p}=0.001$.

\section{Table 3}

\section{Discussion}

In this study, a one-group pretest-posttest design is adopted due to its suitability in understanding the behavioural factors in determining the effect of the treatment on a given sample (Dimitrov, 2003). This research design's usability is well known within the STEM disciplines due to its simplicity to implement and suitable when one group of participants are available to study (Campbell, 1957). However, this research design has some threats to internal validity such as regression to the mean as opposed by (Campbell, 1957). Considering the proof of concept nature of this study, this threat to internal validity needs to be considered as a limitation of this study.

The study revealed interesting insights into the effectiveness of a VR-based interactive FFE virtual environment in FFE's design communication and coordination when compared to the traditional methods (2D based methods) practised across this industry. Time taken to complete the presented task (Table 2) suggests that FFE design choices made using the virtual environment require significantly lesser time compared to the 2D based methods. This also suggests that if there is no sacrifice in the quality of the design choice, there is a direct benefit in using VR as a tool for enabling effective design communication among the critical stakeholders. Furthermore, this result complements the findings of Wang and Dunston (2007) which suggest that usage of VR HMD shortens the completion time and less workload for a task which demands spatial orientation requiring 
local situation awareness. However, it must be noted that task completion time in a virtual environment can be impacted by various levels of fidelity characterisations such as representational, interaction, information and perception of the environment as opposed by Cooper et al., (2018) and various other studies. This does not imply higher the fidelity, higher is the task performance in the virtual environment. For instance, a study by (McMahan et al., 2016) to assess the task completion efficiency using various levels of interaction fidelity found that semi-natural interaction fidelity may have an adverse effect on the task presented than low and high-level interactions, representing “uncanny valley” phenomenon (Mori,1970). Similarly, various studies (e.g. Hamstra et al., 2014) have tested empirically the quantifiable benefits of a higher degree of fidelity. Surprisingly these studies have concluded that enhancement of each characterisation based on the task in hand has beneficial impacts on the task performance and resulting completion time (Dahlstrom et al.,2009). Further, this study didn't consider the impact of using sensory modalities like haptics, which might have a positive impact on the task in hand. However, this must be tested and proven in future studies. The authors were expecting to find a similar or possibly better performance in completing the paper base task because of participants familiarity with the mode of visualisation. However, it is noteworthy to observe that the VR based task significantly outperformed the paper-based task, even though the participants had no or very little experience with VR.

The experiment also revealed that all the design decisions made using paper-based method changed when the participants performed the same task in the virtual environment (Fig.9). This is because spatial perception plays a key role in the context of understanding an architectural space and using that space effectively. Spatial perception is a complex internal information processing task (Marr,1982) and its goal is to estimate, identify, recognize and give meaning to objects and spaces with which the human interacts (Palmer, 2003) which in the context of this study is human-FFE interaction. Studies (e.g. Paes,2017) has pointed out that better spatial perception leads to an enhanced interpretation of spatial elements, which leads to the conclusion that within the immersive virtual 
environment, displayed spatial geometric information of the FFE elements facilitate better understanding and are processed better by the user. However, in the case of paper-based methods, the chances of acquiring such spatial perception are nearly impossible. This finding is noteworthy, as many of the participants in this study had more than 25 years of experience in FFE product design, manufacture and space planning using traditional methods, yet they preferred a different design choice in the virtual environment.

Further, this study also revealed a higher level of user satisfaction in a virtual environment when compared to the 2D based method. Papagiannidis et al., (2013) pointed out that satisfaction is a key ingredient in building consumer loyalty and the end-user satisfaction is a major goal in every user-system interaction. It ought to be noted that, this user satisfaction is the ultimate element that triggers the user's purchase intention of a product or design and this has been proven empirically by various studies like (Papagiannidis et al.,2013). The findings from this study could be applied not only in design decision using virtual reality but also in multi-dimension aspects such as v-commerce or virtual FFE showrooms which allows users to immerse themselves remotely and confidently purchase FFE elements based on the design choice they made in the virtual environment.

This study also probed into the challenges including the infrastructural issues posed by the technology providers. One of such infrastructural issue is the physical weight of the HMD which can hinder the user experience due to physical discomforts. However, the chosen HMD for this study was the basic version of HTC Vive which has been superseded recently by lighter version, thanks to the rapid improvement in ICT during the last few years. Furthermore, FFE contractors raised the concern of interoperability issues that exist between the current BIM authoring tools and immersion and interaction content developing tools. This is one of the major concerns that need to be addressed if the full potential of VR needs to be utilised. Reports have highlighted some limitations with current applications as merely an over-glorified extension of traditional $2 \mathrm{D}$ communications, neglecting other practical and human sensory needs which will normally be engaged when examining physical 
objects (Whyte, 2001; Johnson et al., 2010). It ought to be noted that existing VR applications are merely acting as a vehicle to maintain traditional visualisation practices, ignoring the above mentioned critical factors along with human factors, behaviours and other perceptual and practical needs (Johnson et al., 2010).

\section{Design, architectural and procurement implications}

VR can be considered as one of the most promising technologies in the construction sector and will revolutionise this sector in the next years (Gov.UK, 2018). This study differs from previous literature which focused on VR's application in FFE sector in multi-perspective; a) this study utilises a fully immersive virtual environment which provides spatial cognition to its users like physical environment; b) this study utilised a distributed VR system that replicated the real-life collaborative environment were human-human interaction is critical; c) this study purposes a novel methodology for development and application of an interactive virtual environment and the utilisation of a hybrid user interface that alleviates the limitations of a diegetic and non-diegetic interface. It should be acknowledged that this study used a smaller sample size to test the effectiveness of the system on FFE's workflow. Thus, the findings should not be generalized on an industry-wide level, the findings of this study do support the claim that when implemented properly, VR can enable FFE wide productivity benefits over paper-based methods. Further, the system framework and the findings in this study can be applied not only for the FFE design decision making in the construction sector but also in the virtual commerce aspect of the FFE industry. This will aid the FFE suppliers to switch from physical stores to virtual stores, providing an opportunity to display a vast variety of virtual products without investment in the warehouse space and products focusing more on experience-based marketing. Further, the relevance of such a system for the consumers cannot be overemphasised considering the dynamic purchase behaviour of the consumers as well as the unwillingness of the clients to explore vast shop floor areas to explore the variants of FFE products that are put on display 
(Meadows, 2020). However, it is important to note that one of the key factors contributing to user satisfaction and task productivity in a virtual environment is the richness of the user experience in the virtual environment. Thus, the industry must have to put careful attention during the development of the virtual environment to eliminate the factors that contribute to effects like simulator sickness which will demotivate the user acceptance of VR technology.

\section{Limitations}

The work presented here is a proof of concept employing an experimental design which validates the technological use and exploration of its efficiency compared to the current paper-based and 2D interface-based workflows. The limitations of this study can be related to the test environment, research design and non-consideration of space planning concepts. This experiment did not take place in an actual FFE project set-up, rather it was performed in a controlled environment. Also, at the time of this study, major interoperability issues existed between BIM authoring tools and immersive content creator tools. The content for this study was created using various middleware tools and several iterations before being interactive VR ready. While FFE sectors' BIM adoption is gaining momentum, the implementation of VR into their workflow without addressing the interoperability issues could adversely affect the workflow. Also, additional training might be required for the FFE content developers to create an interactive VR experience which is omitted from the analysis of this study. Therefore, additional investments might be required including training needs over current workflow for organisational-wide adoption of this system. Moreover, the entire system was built to achieve a high-fidelity ecosystem which requires high-end processors and dedicated space which could add on to the investments. Further, even though the single group pretest-posttest design is widely used in studies of this nature, this research design does not account for many confounding variables that may pose threat on the internal validity of the study. Thus, for studies that need to be done on a larger scale, careful consideration of more robust quasi-experimental design must be done. 
Lastly, this study did not consider any principles or guidelines of space planning to assess the quality of design choice made by the participants; rather, the study tries to understand the variations in design decision while using the virtual environment and the effectiveness of networked user environment compared to traditional FFE design selection methods and the resulting satisfaction of the user with respect to the design that they proposed.

\section{Conclusion}

The authors propose a novel methodology for the application of interactive networked VR in FFE design selection process as well as investigating the impact of introducing VR into the BIM workflow. This study is the response to the need for a platform that streamlines design review process in the FFE sector through the engagement of all critical stakeholders assisting them with spatial comprehension, which is a critical factor for any FFE selection and design review process. Thus, this

study extends the synergy between the technology integrating immersive environment which aids in tackling the challenges which exist in perception imposed by conventional 2D methods of design selection and review.

A prototypical interactive networked VR system was presented and discussed. An experimental setup consisting of FFE experts with more than 25 years of experience, architects and end-users were used as the samples. Findings report that the presented framework can highly improve the efficiency, design coordination and productivity as well as highlight the few of the infrastructural issues for scaled-up deployment of this system. Furthermore, this study also investigated the perception of the users before and after the test. Also, the duration for both paper-based and VR based tasks was measured and found that VR tasks required significantly lesser time compared to the traditional method, and a statistically significant difference in the overall time was identified. Furthermore, all the participants proposed a different layout or tested a different design in the VR environment compared to their paper-based proposal. Most of the participants indicated that design 
selection using VR encouraged them to test various layouts and different combination of FFE. The majority of the users identified that the virtual environment provided extreme flexibility in choosing furniture based on their texture, colour and aesthetics as well as being based on the interior space and colour of the rooms, which was impossible when done through conformist methods. Further users reported that the virtual presence of the other participants from the sub-group encouraged the effective testing of different choices and sharing their design ideas and visualising them simultaneously encouraging a collaborative culture in the industry. The satisfaction level of the participants during pre-post treatments was measured and a significant improvement in their satisfaction post-treatment was observed. However, some of the users reported infrastructural issues, such as the weight of the HMD, as a concern that may restrict some users from using this system in the long run. This study contributes to the body of knowledge by the empirical demonstration of the potential of interactive distributed VR for FFE design selection process compared to the present paper-based approach, with the aid of industry-developed BIM and industry experts. 


\section{References}

Allen, M. (2017) The SAGE Encyclopedia of Communication Research Methods [online]. SAGE Publications. [Accessed 15 November 2019].

AMA Research, (2014) Supply Chain Review of the Furniture Industry Market Report - UK 20142018 Analysis. Available from: https://www.amaresearch.co.uk/products/furniture-industrysupply-chain-2014 [Accessed 02 February 2019].

Ambroggio, L., Smith, M.J. and Shah, S.S. (2012) Editorial Commentary: Quasi-Experimental and Interrupted Time-Series Design. Journal of the Pediatric Infectious Diseases Society [online]. 1 (3), pp.187-189. [Accessed 03 November 2019].

Autodesk, (2019) what You can do with Revit. Available from: https://www.autodesk.co.uk/products/revit/architecture [Accessed 15 February 2019].

Azhar, S. (2017) Role of visualization technologies in safety planning and management at construction jobsites. Procedia Engineering [online]. 171 pp.215-226. [Accessed 23 August 2020].

Barbosa, F., Woetzel, J., Mischke, J., Ribeirinho, M.J., Sridhar, M., Parsons, M., Bertram, N. and Brown, S., (2017) Reinventing Construction: A Route to Higher Productivity [online]. McKinsey Global Institute. [Accessed 19 May 2018].

Barnes, M. (1988) Construction project management. International Journal of Project Management [online]. 6 (2), pp.69-79. [Accessed 15 May 2018].

Berg, L.P. and Vance, J.M. (2017) Industry use of virtual reality in product design and manufacturing: a survey. Virtual Reality [online]. 21 (1), pp.1-17. [Accessed 03 June 2019].

Biemans, W.G. and Brand, M.J. (1995) Reverse marketing: a synergy of purchasing and relationship marketing. International Journal of Purchasing and Materials Management [online]. 31 (2), pp.28-37. [Accessed 06 June 2019].

Birkett.A (2019) 8 Ways to Measure Satisfaction (and Improve UX). Available from: https://cxl.com/blog/8-ways-to-measure-ux-satisfaction/ [Accessed 2 September 2019].

Blalock Jr, H.M. (2018) Causal Inferences in Nonexperimental Research [online]. UNC Press Books. [Accessed 3 November 2019].

Bouchlaghem, N. and Liyanage, I. (1996) Virtual reality applications in the UK's construction industry. Cib Report [online]. pp.89-94. [Accessed 04 March 2019].

Campbell, D.T. (1957) Factors relevant to the validity of experiments in social settings. Psychological Bulletin [online]. 54 (4), pp.297. [Accessed 29 May 2020]. 
Chakraborty, G., Kikuchi, D., Sawamoto, J. and Yokoha, H., eds. (2013) Perception Delay and its Estimation Analyzing EEG Signal[online]. Lausanne, Switzerland, IEEE. Available from: https://ieeexplore.ieee.org/document/6617427. [Accessed 23 August].

Chalhoub, J. and Ayer, S.K. (2018) Using Mixed Reality for electrical construction design communication. Automation in Construction [online]. 86 pp.1-10. [Accessed 13 July 2019].

Chinowsky, P.S. and Rojas, E.M. (2003) Virtual teams: Guide to successful implementation. Journal of Management in Engineering [online]. 19 (3), pp.98-106. [Accessed 12 October 2019].

Cotey, E., (2017) Integrating Revit into the Office Furniture Cycle. Barrington: AutoSpec corp.

Creusen, M.E. and Schoormans, J.P. (2005) The different roles of product appearance in consumer choice. Journal of Product Innovation Management [online]. 22 (1), pp.63-81. [Accessed 26 May 2019].

Dawood, N., Sriprasert, E., Mallasi, Z. and Hobbs, B. (2003) Development of an integrated information resource base for 4D/VR construction processes simulation. Automation in Construction [online]. 12 (2), pp.123-131. [Accessed 12 July 2020].

de Klerk, R., Duarte, A.M., Medeiros, D.P., Duarte, J.P., Jorge, J. and Lopes, D.S. (2019) Usability studies on building early-stage architectural models in virtual reality. Automation in Construction [online]. 103 pp.104-116. [Accessed 09 November 2019].

Dimitrov, D.M. and Rumrill Jr, P.D. (2003) Pretest-posttest designs and measurement of change. Work [online]. 20 (2), pp.159-165. [Accessed 12 December 2019].

Družić, G. and Basarac Sertić, M. (2015) A roadmap of actions aiming at ensuring furniture industry production growth: panel analysis. Economic Research-Ekonomska istrå̊3/4ivanja [online]. 28 (1), pp.572-582. [Accessed 19 May 2020].

Du, J., Zou, Z., Shi, Y. and Zhao, D. (2018) Zero latency: Real-time synchronization of BIM data in virtual reality for collaborative decision-making. Automation in Construction [online]. 85 pp.51-64. [Accessed 11 April 2019].

Du, J., Zou, Z., Shi, Y. and Zhao, D. (2018) Zero latency: Real-time synchronization of BIM data in virtual reality for collaborative decision-making. Automation in Construction [online]. 85 pp.51-64. [Accessed 19 June 2020].

Eppler, M.J. and Platts, K.W. (2009) Visual strategizing: The systematic use of visualization in the strategic-planning process. Long Range Planning [online]. 42 (1), pp.42-74. [Accessed 22 May 2020]. 
Ergan, S., Radwan, A., Zou, Z., Tseng, H. and Han, X. (2019) Quantifying human experience in architectural spaces with integrated virtual reality and body sensor networks. Journal of Computing in Civil Engineering [online]. 33 (2), pp.04018062. [Accessed 08 August 2019].

Fazio, R.H. (1990) A practical guide to the use of response latency in social psychological research. [online]. [Accessed 21 August 2019].

Fidlschuster, k. (2007) FF\&E: The Magic Formula for Hotel Operators-a Nightmare for Investors? Available from: https://media.hotelwebservice.com/media/hotour/docs/ff_e_the_magic_formula_for_hotel_operators_-_a_nightmare_for_investors1.pdf. [Accessed 12 August 2019].

Garcia, G. (2017) the Transformative Tech Revolution: Architecture, Engineering, \& Construction. Available from: https://arvrjourney.com/the-transformative-tech-revolutionarchitecture-engineering-construction-814565a0f4fc [Accessed 15 February 2019].

Getuli, V., Capone, P., Bruttini, A. and Isaac, S. (2020) BIM-based immersive Virtual Reality for construction workspace planning: A safety-oriented approach. Automation in Construction [online]. 114 pp.103160. [Accessed 23 August 2020].

Gogtay, N. and Thatte, U. (2016) Samples and their size: The bane of researchers [Part II]. J Assoc Phy Ind [online]. 64 pp.68-71. [Accessed 26 July 2020].

Greenwood, D., Horne, M., Thompson, E.M., Allwood, C.M., Wernemyr, C. and Westerdahl, B. (2008) Strategic perspectives on the use of virtual reality within the building industries of four countries. Architectural Engineering and Design Management [online]. 4 (2), pp.85-98. [Accessed 05 March 2019].

Hall, P. and Tewdwr-Jones, M. (2010) Urban and Regional Planning [online]. 5th ed. London: Routledge. [Accessed 09 March 2019].

Hartless, J.F., Ayer, S.K., London, J.S. and Wu, W. (2020) Comparison of Building Design Assessment Behaviors of Novices in Augmented-and Virtual-Reality Environments. Journal of Architectural Engineering [online]. 26 (2). [Accessed 22 August 2020].

Heydarian, A., Carneiro, J.P., Gerber, D., Becerik-Gerber, B., Hayes, T. and Wood, W. (2015) Immersive virtual environments versus physical built environments: A benchmarking study for building design and user-built environment explorations. Automation in Construction [online]. 54 pp.116-126. [Accessed 11 March 2019].

Hilfert, T., Teizer, J. and König, M., eds. (2016) ISARC. Proceedings of the International Symposium on Automation and Robotics in Construction [online]. IAARC Publications. Available from: https://www.researchgate.net/profile/Jochen_Teizer2/publication/309262801_First_Person_ 
Virtual_Reality_for_Evaluation_and_Learning_of_Construction_Site_Safety/links/5811b90 c08ae009606be8ca7/First-Person-Virtual-Reality-for-Evaluation-and-Learning-ofConstruction-Site-Safety.pdf. [Accessed 23 August 2020].

Hoffman, H.G., Richards, T., Coda, B., Richards, A. and Sharar, S.R. (2003) The illusion of presence in immersive virtual reality during an fMRI brain scan. CyberPsychology \& Behavior [online]. 6 (2), pp.127-131. [Accessed 05 May 2019].

Hong, Y. and Michalatos, P. (2016) Lumispace: A VR architectural daylighting design system. In: Anon. (2016) SIGGRAPH ASIA 2016 Virtual Reality Meets Physical Reality: Modelling and Simulating Virtual Humans and Environments [online]. pp.1-2. [Accessed 12 July 2020]. HTC (2019) Available from: https://www.vive.com/uk/comparison/ [Accessed 11 April 2019].

Irkett, A. (2019) 8 Ways to Measure User Satisfaction. Available from: https://conversionxl.com/blog/8-ways-to-measure-ux-satisfaction/[Accessed 21 August 2019].

Jackson, B. (2015) what is Virtual Reality?. Available from: https://www.marxentlabs.com/what-isvirtual-reality/ [Accessed 29 May 2018].

Jiao, Y., Zhang, S., Li, Y., Wang, Y. and Yang, B. (2013) Towards cloud augmented reality for construction application by BIM and SNS integration. Automation in Construction [online]. 33 pp.37-47. [Accessed 11 May 2019].

Johansson, M., Roupé, M. and Viklund Tallgren, M., eds. (2014) Fusion-Proceedings of the 32nd eCAADe Conference-Volume 2 (eCAADe 2014) [online]. Available from: http://publications.lib.chalmers.se/records/fulltext/201746/local 201746.pdf. [Accessed 12 August 2019].

Johnson, A., Thompson, E. and Coventry, K., eds. (2010) Human Perception, Virtual Reality and the Built Environment:14th International Conference Information Visualisation [online]. London, UK, 26-29 July. Available from: https://ieeexplore.ieee.org/abstract/document/5571123. [Accessed 15 February 2019].

Johnston, P. (2011) Inside View: How can BIM Help the Interior Design Process. Available from: WWW. H FMMAG A Z I N E. C OM [Accessed 07 July 2019].

Jones, R.A. and Kapple, W.H. (1975) Kitchen Planning Principles: Equipment, Appliances [online]. [Accessed 21 July 2019].

Kang, L.S., Moon, H.S., Dawood, N. and Kang, M.S. (2010) Development of methodology and virtual system for optimised simulation of road design data. Automation in Construction [online]. 19 (8), pp.1000-1015. [Accessed 23 August 2020]. 
Khanzode, A., Fischer, M. and Hamburg, S. (2000) Effect of information standards on the designconstruction interface: Case examples from the steel industry. In: Anon. (2000) Computing in Civil and Building Engineering (2000) [online]. pp.804-811. [Accessed 22 May 2020].

Laval Virtual (2017) Laval Virtual. Available from: https://www.laval-virtual.org/[Accessed 20 August 2018].

Li, X., Wu, P., Shen, G.Q., Wang, X. and Teng, Y. (2017) Mapping the knowledge domains of Building Information Modeling (BIM): A bibliometric approach. Automation in Construction [online]. 84 pp.195-206. [Accessed 21 July 2019].

Lin, J., Cao, L. and Li, N. (2020) How the completeness of spatial knowledge influences the evacuation behaviour of passengers in metro stations: A VR-based experimental study. Automation in Construction [online]. 113 pp.103136. [Accessed 02 August 2020].

Lin, K., Son, J.W. and Rojas, E.M. (2011) A pilot study of a 3D game environment for construction safety education. Journal of Information Technology in Construction (ITcon) [online]. 16 (5), pp.69-84. [Accessed 23 May 2019].

Miltiadis, C. (2015) Virtual Architecture in a Real-time, Interactive, Augmented Reality Environment-project Anywhere and the potential of Architecture in the age of the Virtual. [online]. [Accessed 21 June 2019].

NBS (2016) What is Building Information Modeling (BIM)? Available from: https://www.thenbs.com/knowledge/what-is-building-information-modellingbim [Accessed 17 January 2018].

Oblak, L., Pirc Barčić, A., Klarić, K., Kitek Kuzman, M. and Grošelj, P. (2017) Evaluation of factors in buying decision process of furniture consumers by applying AHP method. Drvna Industrija: Znanstveni Časopis Za Pitanja Drvne Tehnologije [online]. 68 (1), pp.37-43. [Accessed 30 August 2019].

Oh, H., Yoon, S. and Hawley, J. (2004) What virtual reality can offer to the furniture industry. Journal of Textile and Apparel, Technology and Management [online]. 4 (1), pp.1-17. [Accessed 03 March 2019].

Padilla, L.M., Creem-Regehr, S.H., Hegarty, M. and Stefanucci, J.K. (2018) Decision making with visualizations: a cognitive framework across disciplines. Cognitive Research: Principles and Implications [online]. 3 (1), pp.29. [Accessed 19 July 2019].

Pakarinen, T. and Asikainen, A. (2001) Consumer segments for wooden household furniture. European Journal of Wood and Wood Products [online]. 59 (3), pp.217-227. [Accessed 24 August 2019]. 
Pakhale, P.D. and Pal, A. (2020) Digital project management in infrastructure project: a case study of Nagpur Metro Rail Project. Asian Journal of Civil Engineering [online]. pp.1-9. [Accessed 20 May 2020].

Panetta, K. (2017) Top trends in the Gartner hype cycle for emerging technologies, 2017. Smarter with Gartner [online]. 5 [Accessed 24 June 2019

Photon (2019) We make Multiplayer Simple. Available from: https://www.photonengine.com/ [Accessed 29 September 2019].

Prabhakaran, A., Mahamadu, A.-M. ed, Mahdjoubi, L. and Manu, P. (2018) An approach for integrating mixed reality into BIM for early-stage design coordination. In: The 9th International Conference on Engineering Project and Production Management (EPPM) 2018, Cape Town, South Africa. [In Press] Available from: http://eprints.uwe.ac.uk/37844

Price, c., Jhangiani, R. and Chiang, C. (2016) Quasi-Experimental Research. Available from: https://opentextbc.ca/researchmethods/chapter/quasi-experimental-research/ [Accessed 11 July 2019].

Puri, D. (2017) What are the Advantages of OOP? Available from: https://www.quora.com/What-arethe-advantages-of-OOP [Accessed 20 February 2019].

RACEC, E., BUDULAN, S. and VELLIDO, A. (2016) Computational Intelligence in architectural and interior design: a state-of-the-art and outlook on the field. [online]. [Accessed 19 May 2020].

Rahimian, F.P., Chavdarova, V., Oliver, S., Chamo, F. and Amobi, L.P. (2019) OpenBIM-Tango integrated virtual showroom for offsite manufactured production of self-build housing. Automation in Construction [online]. 102 pp.1-16. [Accessed 12 August 2019].

Rasmussen, M., Gade, A. N. and Jensen, R. L., eds. (2017) Bridging the Gap between Actors and Digital Tools in a Furnishing Design Process: [online]. Aalborg, 26-27- January. When Social Science meets BIM and LEAN. Available from: https://www.semanticscholar.org/paper/Bridging-the-Gap-between-Actors-and-Digitaltools-a-Rasmussen-Gade/f4892b43f1d2a88de56005dde48556954eaf67d9. [Accessed 12 July 2019].

Roy, A. and Tai, S.T. (2003) Store environment and shopping behaviour: the role of imagery elaboration and shopping orientation. Journal of International Consumer Marketing [online]. 15 (3), pp.71-99. [Accessed 03 August 2019].

Saeidi, S., Zhu, Y., Lifkooee, M.Z., Mollazadeh, M. and Li, X. (2019) Co-Presence in a Shared Virtual Environment (SVE): A Case Study of Highway Work Zone Construction. In: 
Anon.(2019) ICCREM 2019: Innovative Construction Project Management and Construction Industrialization [online]. American Society of Civil Engineers Reston, VA, pp.490-497. [Accessed 19 August 2020].

Sauro, J. (2012) Available from: https://measuringu.com/seq10/ [Accessed 12 June 2019].

Shi, Y., Du, J. and Worthy, D.A. (2020) The impact of engineering information formats on learning and execution of construction operations: A virtual reality pipe maintenance experiment. Automation in Construction [online]. 119 pp.103367. [Accessed 23 August 2020].

Springfield Supplies \& Projects (2019) 2019 - 2020 Educational Furniture Handbook. Available from: https://www.springfieldeducationalfurniture.co.uk/downloads [Accessed 19 September 2019].

Sydora, C. and Stroulia, E., eds. (2019) Proceedings of the 6th ACM International Conference on Systems for Energy-Efficient Buildings, Cities, and Transportation [online]. Association for Computing Machinery. Available from: https://doi.org/10.1145/3360322.3360997. [Accessed 19 May 2020].

Tantawy, D. (2015) The Furniture Layout Using the Interior Design Guidelines. International Journal of Sciences: Basic and Applied Research. 21 (2), pp.160-178.

The British Furniture Confederation (2018) About the Industry. Available from: http://britishfurnitureconfederation.org.uk/about-the-industry/ [Accessed 06 May 2018]. Unity3D, (2019) Unity3d. Available from: https://unity3d.com/ [Accessed 16 February 2019].

Virzi, R.A., Sokolov, J. L. and Karis, D., eds. (1996) Usability Problem Identification using both Low-and High-Fidelity Prototypes: Proceedings of the SIGCHI Conference on Human Factors in Computing Systems [online]. Waltham, USA, 13-18 April. ACM. Available from: https://www.researchgate.net/profile/Demetrios_Karis/publication/221519756_Usability_P roblem Identification Using Both Low- and HighFidelity_Prototypes/links/56baa93108ae3af6847d8bc9.pdf. [Accessed 15 March 2019].

Walasek, D. and Barszcz, A. (2017) Analysis of the adoption rate of building information modeling [BIM] and its return on investment [ROI]. Procedia Engineering [online]. 172 pp.1227-1234. [Accessed 06 July 2019].

Wallach, S., Safir, M., Horef, R. and Huber, E. (2012) Presence in virtual reality: Importance and methods to increase it. Systems in the Health Care using Agents and Virtual Reality. pp.107123.

Wang, X. and Dunston, P.S. (2007) Design, strategies, and issues towards an augmented reality-based construction training platform. Journal of Information Technology in Construction (ITcon) [online]. 12 (25), pp.363-380. [Accessed 21 August 2019]. 
Whyte, J. (2001) Virtual reality as a visualisation tool: benefits and constraints. International Journal of IT in Architecture, Engineering and Construction (IT-AEC) [online]. 2 (4), pp.216-224. [Accessed 01 March 2019].

Winestock, N. (2018) VR and Diegetic Interface: Don't Break the Experience. Available from: https://uxdesign.cc/vr-diegetic-interfaces-dont-break-the-experience554f210b6e46 [Accessed 11 August 2019].

Wolfartsberger, J. (2019) Analyzing the potential of Virtual Reality for engineering design review. Automation in Construction [online]. 104 pp.27-37. [Accessed 23 August 2020].

WorkSpace

(2018) Workspace

Commercial

Furniture. Available

from: https://www.workspace.com.au/ [Accessed 05 August 2018].

Yan, W., Culp, C. and Graf, R. (2011) Integrating BIM and gaming for real-time interactive architectural visualization. Automation in Construction [online]. 20 (4), pp.446-458. [Accessed 05 September 2019].

Yoon, S., Oh, H. and Cho, J.Y. (2010) Understanding furniture design choices using a 3D virtual showroom. Journal of Interior Design [online]. 35 (3), pp.33-50. [Accessed 21 September 2019].

Zhang, Y., Liu, H., Zhao, M. and Al-Hussein, M. (2019) User-centered interior finishing material selection: An immersive virtual reality-based interactive approach. Automation in Construction [online]. 106 pp.102884. [Accessed 12 July 2020]. 


\begin{tabular}{|l|c|l|}
\hline \multicolumn{2}{|c|}{$\longrightarrow$ Intervention } & \multicolumn{1}{c|}{ Posttest } \\
\hline $\mathrm{O}_{1}$ & $\mathrm{X}_{1}$ & $\mathrm{O}_{2}$ \\
\hline $\begin{array}{l}\text { Paper based design selection } \\
\text { for an office and meeting area } \\
\text { using 2D FFE catalogue }\end{array}$ & Full immersive VR & $\begin{array}{l}\text { VR based design selection for } \\
\text { office and meeting area using } \\
\text { dynamic FFE catalogue. }\end{array}$ \\
\hline
\end{tabular}

Figure 1: One-Group Pretest- Posttest visual representation (adopted from Allen, (2017))

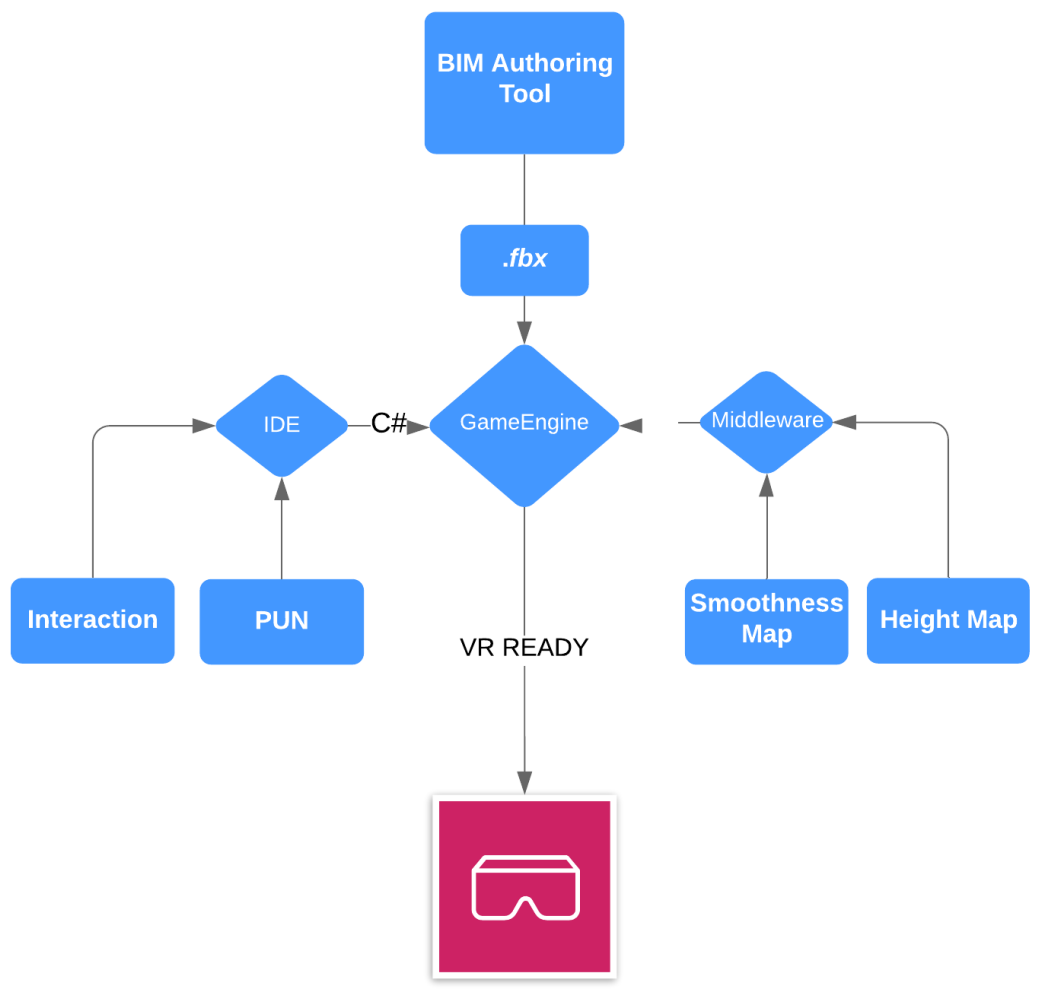

Figure 2: System Architecture 


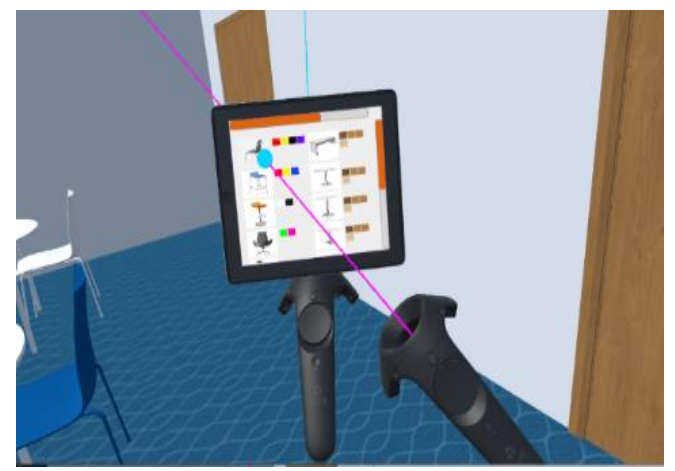

Figure 3-Dynamic \& Interactive virtual catalogue

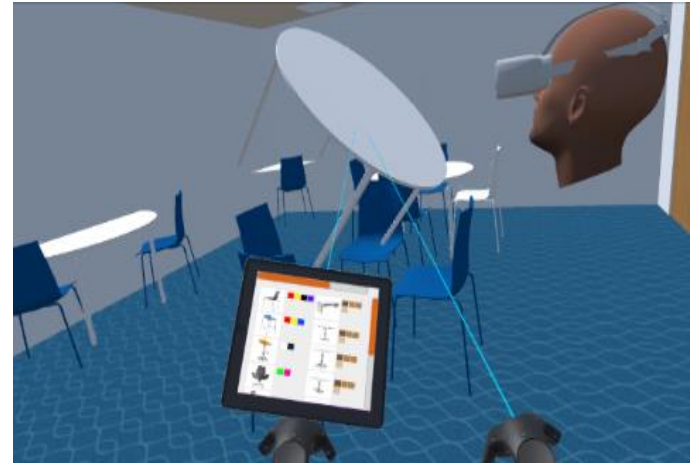

Figure 5-Users Interacting with FFE

elements

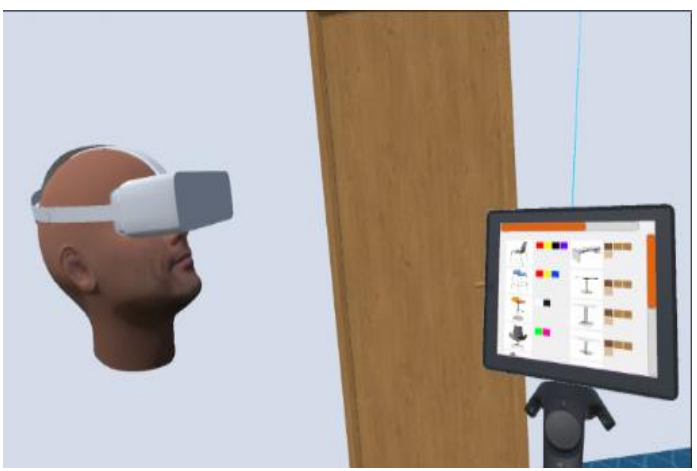

Figure 4-Multi-users testing design

choices in virtual environment

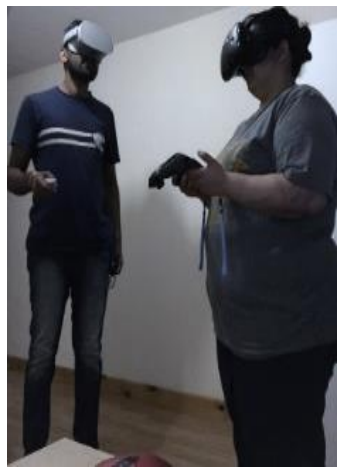

Figure 6-Users in

physical world 


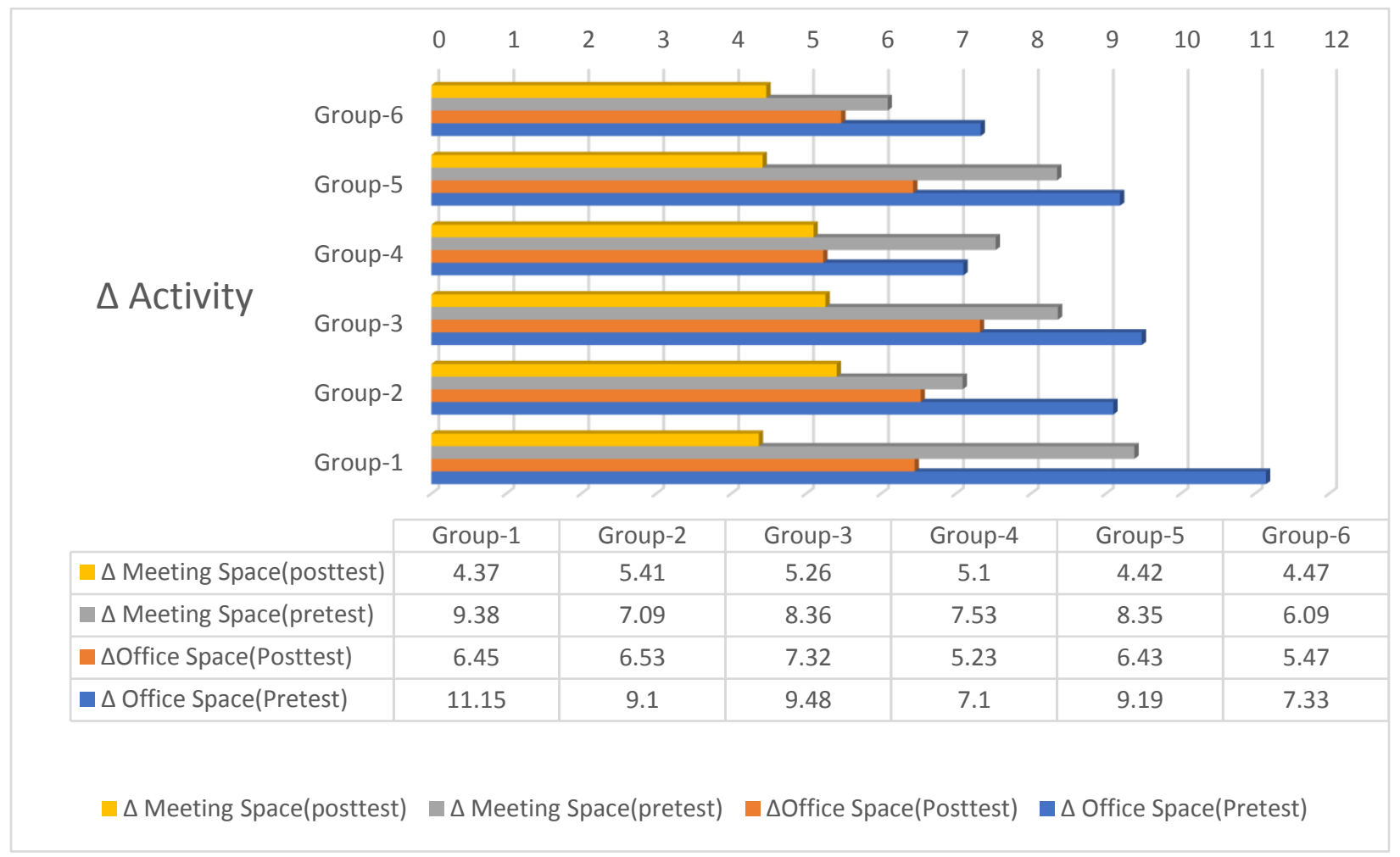

Figure 7-Time taken to complete each activity
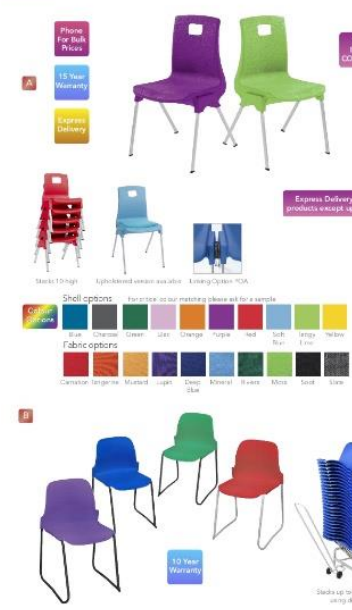

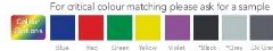

Fare Oastons $=$

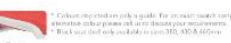

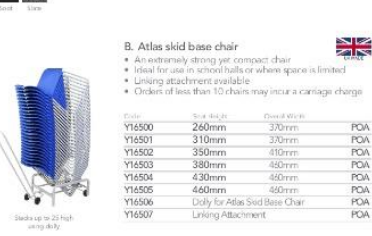

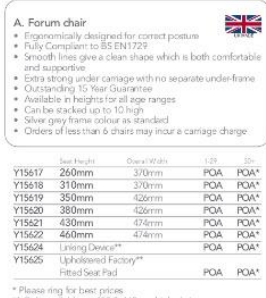

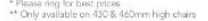

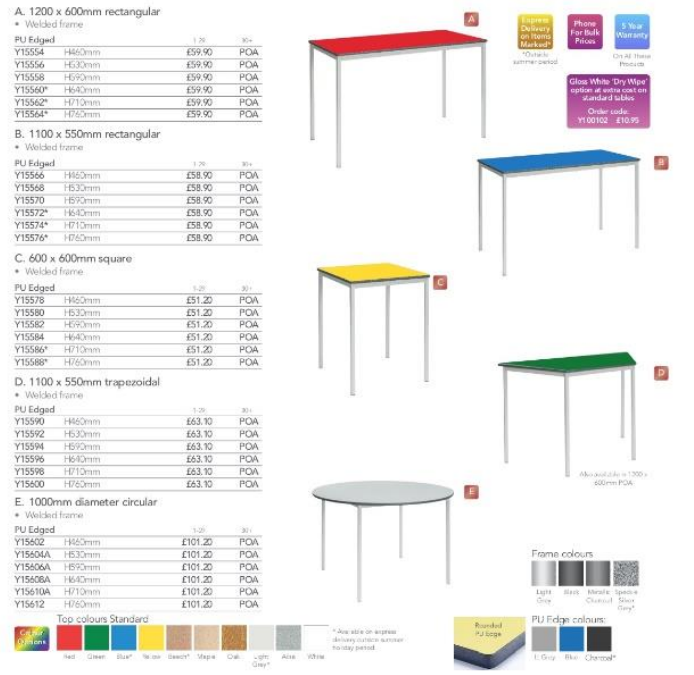

Figure 8- 2D FFE Catalogue (Springfield, 2019) 

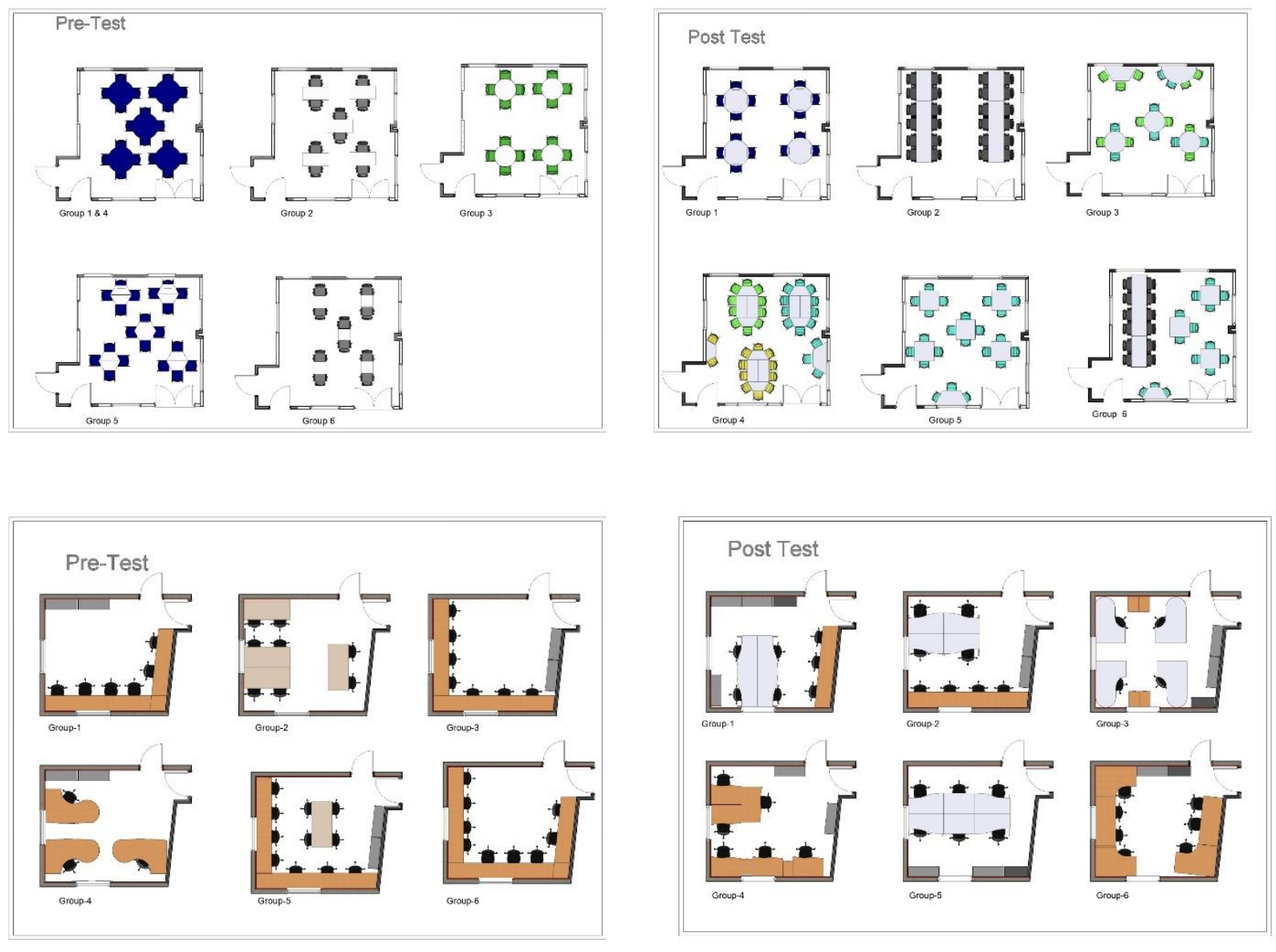

Figure 9-(A)-Pre-test Meeting Space, (B)-Post-test Meeting Space, (C)-Pre-test Office Space, (D)Post-test Office Space

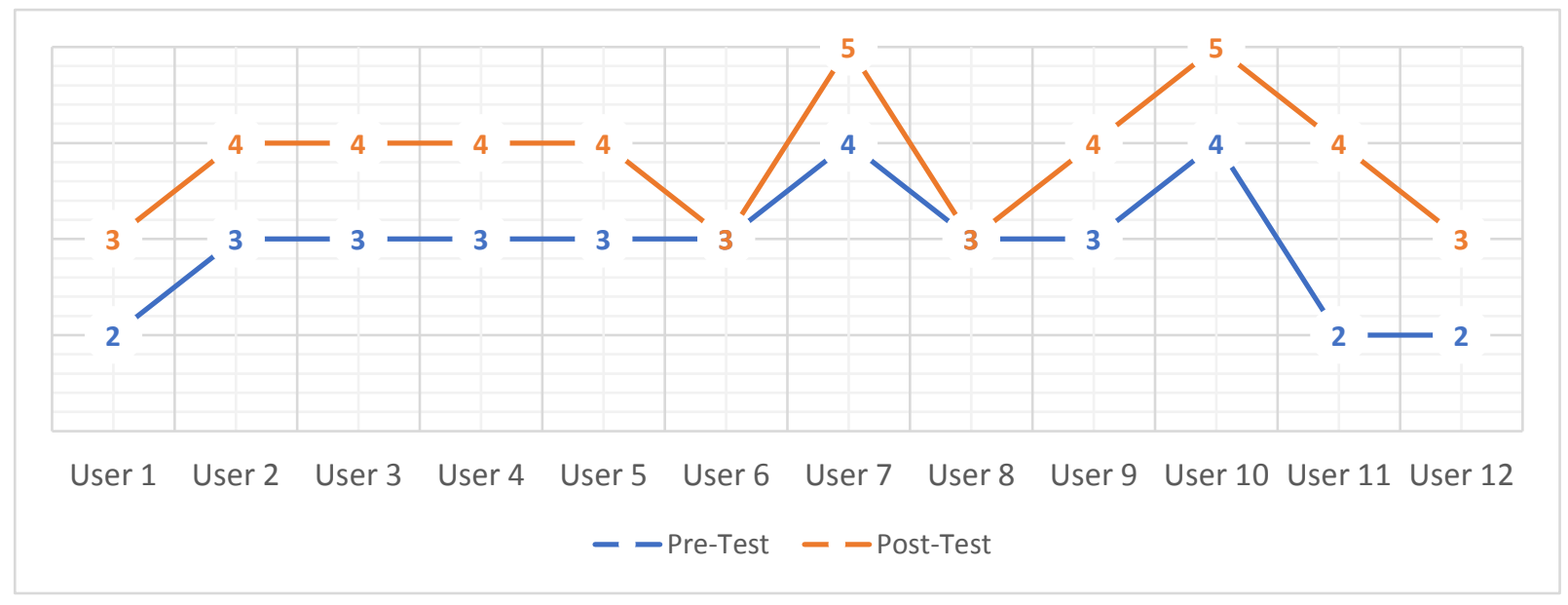

Figure 10-User Satisfaction level 


\begin{tabular}{|l|l|}
\hline \multicolumn{2}{|l|}{ List of Figures } \\
\hline Figure 1 & One-Group Pretest- Posttest visual representation (adopted from Allen, (2017) \\
\hline Figure 2 & System Architecture \\
\hline Figure 3 & Dynamic \& Interactive virtual catalogue \\
\hline Figure 4 & Multi-users testing design choices in virtual environment \\
\hline Figure 5 & Users Interacting with FFE elements \\
\hline Figure 6 & Users in physical world \\
\hline Figure 7 & Time taken to complete each activity \\
\hline Figure 8 & 2D FFE Catalogue (Springfield, 2019) \\
\hline Figure 9 & (A)-Pre-test Meeting Space, (B)-Post-test Meeting Space, (C)-Pre-test Office \\
& Space, (D)-Post-test Office Space \\
\hline Figure 10 & User Satisfaction level \\
\hline
\end{tabular}


Tables

Table 1-Participant's Background Information

\begin{tabular}{|l|l|l|l|l|c|}
\hline Participant ID & Age & Gender & Years of Experience & Designation & Group ID \\
\hline VRFFE201901 & 59 & M & 30 & FFE design specialist (Contractor) & 1 \\
\hline VRFFE201902 & 57 & M & 27 & FFE design specialist (Contractor) & 3 \\
\hline VRFFE201903 & 51 & M & 25 & FFE design specialist (Contractor) & 2 \\
\hline VRFFE201904 & 53 & M & 28 & FFE design specialist (Contractor) & 5 \\
\hline VRFFE201905 & 48 & M & 25 & FFE design specialist (Contractor) & 3 \\
\hline VRFFE201906 & 36 & F & 6 & Architect & 4 \\
\hline VRFFE201907 & 28 & M & 4 & Architect & 5 \\
\hline VRFFE201908 & 35 & M & 11 & Architect & 6 \\
\hline VRFFE201909 & 24 & F & 3 & End-user (Nurse) & 4 \\
\hline VRFFE2019010 & 27 & F & 2 & End-user (Nurse) & 1 \\
\hline VRFFE2019011 & 25 & M & 9 & 4 & End-user (Teacher) \\
\hline VRFFE2019012 & 32 & F & & & 6 \\
\hline
\end{tabular}

Table 1-Independent sample t-test for significance in time between treatments

\begin{tabular}{|c|c|c|c|c|c|c|c|c|c|c|}
\hline \multirow{3}{*}{\multicolumn{2}{|c|}{$\mathrm{n}=12$}} & \multicolumn{2}{|c|}{$\begin{array}{ll}\text { Levene's } & \text { Test } \\
\text { Equality } \\
\text { Variances }\end{array}$} & \multicolumn{7}{|c|}{ t-test for Equality of Means } \\
\hline & & \multirow[t]{2}{*}{$\mathrm{F}$} & \multirow[t]{2}{*}{ Sig. } & \multirow[t]{2}{*}{$\mathrm{t}$} & \multirow[t]{2}{*}{ df } & \multirow{2}{*}{$\begin{array}{l}\text { Sig. } \\
(2- \\
\text { tailed) }\end{array}$} & \multirow[t]{2}{*}{$\begin{array}{l}\text { Mean } \\
\text { Difference }\end{array}$} & \multirow[t]{2}{*}{$\begin{array}{l}\text { Std. Error } \\
\text { Difference }\end{array}$} & \multicolumn{2}{|c|}{$\begin{array}{l}95 \% \text { Confidence Interval } \\
\text { of the Difference }\end{array}$} \\
\hline & & & & & & & & & Lower & Upper \\
\hline \multirow[b]{2}{*}{$\begin{array}{l}0 \\
0 \\
\tilde{~} \\
0 \\
0 \\
0 \\
0 \\
0\end{array}$} & $\begin{array}{l}\text { Equal } \\
\text { variances } \\
\text { assumed }\end{array}$ & 1.693 & 0.222 & 3.661 & 10 & 0.004 & 152.00000 & 41.52309 & 59.48080 & 244.51920 \\
\hline & $\begin{array}{l}\text { Equal } \\
\text { variances not } \\
\text { assumed }\end{array}$ & & & 3.661 & 7.543 & 0.007 & 152.00000 & 41.52309 & 55.22924 & 248.77076 \\
\hline \multirow{2}{*}{ 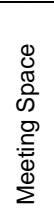 } & $\begin{array}{l}\text { Equal } \\
\text { variances } \\
\text { assumed }\end{array}$ & 4.159 & 0.069 & 5.526 & 10 & 0.000 & 176.16667 & 31.87833 & 105.13733 & 247.19601 \\
\hline & $\begin{array}{l}\text { Equal } \\
\text { variances not } \\
\text { assumed }\end{array}$ & & & 5.526 & 6.232 & 0.001 & 176.16667 & 31.87833 & 98.86208 & 253.47126 \\
\hline
\end{tabular}


Table 2-Independent sample t-test for significance in satisfaction

\begin{tabular}{|c|c|c|c|c|c|c|c|c|c|c|}
\hline \multirow{3}{*}{\multicolumn{2}{|c|}{$\mathrm{n}=12$}} & \multicolumn{2}{|c|}{ 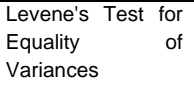 } & \multicolumn{7}{|c|}{ t-test for Equality of Means } \\
\hline & & \multirow[t]{2}{*}{$\mathrm{F}$} & \multirow[t]{2}{*}{ Sig. } & \multirow[t]{2}{*}{$\mathrm{t}$} & \multirow[t]{2}{*}{$d f$} & \multirow{2}{*}{$\begin{array}{l}\text { Sig. } \\
(2- \\
\text { tailed) }\end{array}$} & \multirow[t]{2}{*}{$\begin{array}{l}\text { Mean } \\
\text { Difference }\end{array}$} & \multirow[t]{2}{*}{$\begin{array}{l}\text { Std. Error } \\
\text { Difference }\end{array}$} & \multicolumn{2}{|c|}{$\begin{array}{l}95 \% \text { Confidence Interval } \\
\text { of the Difference }\end{array}$} \\
\hline & & & & & & & & & Lower & Upper \\
\hline \multirow{2}{*}{ 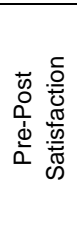 } & $\begin{array}{l}\text { Equal } \\
\text { variances } \\
\text { assumed }\end{array}$ & 0.216 & 0.646 & -4.84 & 22 & 0.001 & -1.16667 & 0.2410 & -1.6664 & -0.66686 \\
\hline & $\begin{array}{l}\text { Equal } \\
\text { variances } \\
\text { not } \\
\text { assumed }\end{array}$ & & & -4.84 & 21.95 & 0.001 & -1.16667 & 0.2410 & -1.66652 & -0.66681 \\
\hline
\end{tabular}

